\title{
Revised comparison and analysis of severe magnetic storm effects measured over Istanbul and Rome
}

\author{
Harutyun Agopyan \\ Vocational School of Technical Sciences, Telecommunication Program, Istanbul University, Turkey
}

\begin{abstract}
Geomagnetic Storms (GS) and Ionospheric Storms (IS) for high geomagnetic activity conditions are studied in Istanbul (IST) and in Rome (RO). Further and revised results that led to new interpretations are briefly presented here following a previous paper on the severe storm effects on the ionosphere over Istanbul. The series of storms started on 28th October 1968 and went on to 2nd November 1968 with the geomagnetic index Kp reaching values up to 8 . Deviations of the critical frequency of the $F 2$ layer, $\Delta f o F 2(\%)$, from monthly medians up to $100 \%$ were observed. Power spectral results show here that not only the Diurnal Planetary Waves (PW) of 2.3 day periodicity but also tidal waves with semidiurnal (12h), teridiurnal (8h) and quaterdiurnal (6h) characteristic times are present.
\end{abstract}

Key words radio propagation - geomagnetic and ionospheric storm

\section{International observations on geomagnetic and ionospheric variations}

A model comparison of noon International Reference Ionosphere (IRI, Bilitza, 1988) profiles obtained from both ionospheric stations of Istanbul (IST; $41^{\circ} \mathrm{N} ; 29^{\circ} \mathrm{E}, \mathrm{LT}=(\mathrm{UT}+2 \mathrm{~h})$, $\left.\mathrm{DIP}=57^{\circ} .2, L=1.6\right)$ and Rome $\left(\mathrm{RO} ; 41^{\circ} \mathrm{N}\right.$; $\left.12^{\circ} \mathrm{E}, \mathrm{LT}=(\mathrm{UT}+1 \mathrm{~h}), \mathrm{DIP}=57^{\circ} .4 \mathrm{~L}=1.6\right)$ is reported in fig. 1. Some references to these procedures can be found in Davies, 1981; Agopyan, 1982; Titheridge, 1988; Rawer and Bilitza, 1989; Schunk, 1996 and Bilitza, 2008. The

Mailing address: Dr. Harutyun Agopyan, Istanbul University, Vocational School of Technical Sciences, Telecommunication Program, 34320 Avcilar, Istanbul, Turkey: e-mail: harutyun@istanbul.edu.tr electron density $(\mathrm{Ne})$ noon profiles for the two stations, obtained by the IRI model, show a slab thickness of $\tau \sim 150 \mathrm{~km}$ for the $F$ region.

A similarity between the two stations situated at the same $L$ shell (1.6) and with only $\Delta \mathrm{h}=1 \mathrm{~h}$ difference of universal standard time (UTS) as well a slightly different behavior typical of disturbed days, can also be clearly seen in fig. 2.

The plasmapause is typically located at $L=4-6$ but may be found at $L \sim 2$ during very active periods; for both observation sites at $L=1.6$ and with (magnetic planetary index Kp) Kp $\geq 7$ then the saturation of the protonospheric reservoir value should take (see Kamide and Richmond, 1986) ts $=0.17(\mathrm{~L})^{4}=\simeq 1.1$ days, so that one day becomes insufficient for its replenishment as seen in fig. 3 .

The method of analysis applied to RO and IST measurements used here was described in previous papers (Bulat et al., 1997 and Agopyan, 2002). The hourly values of frequency ( $\mathrm{MHz})$ measurements of $\triangle f o F 2(\%)$ are based on $f_{o F} 2$ Bibl ionosonde data from Istanbul University Ionosphere Research Station Ayazaga IST-IIAI 


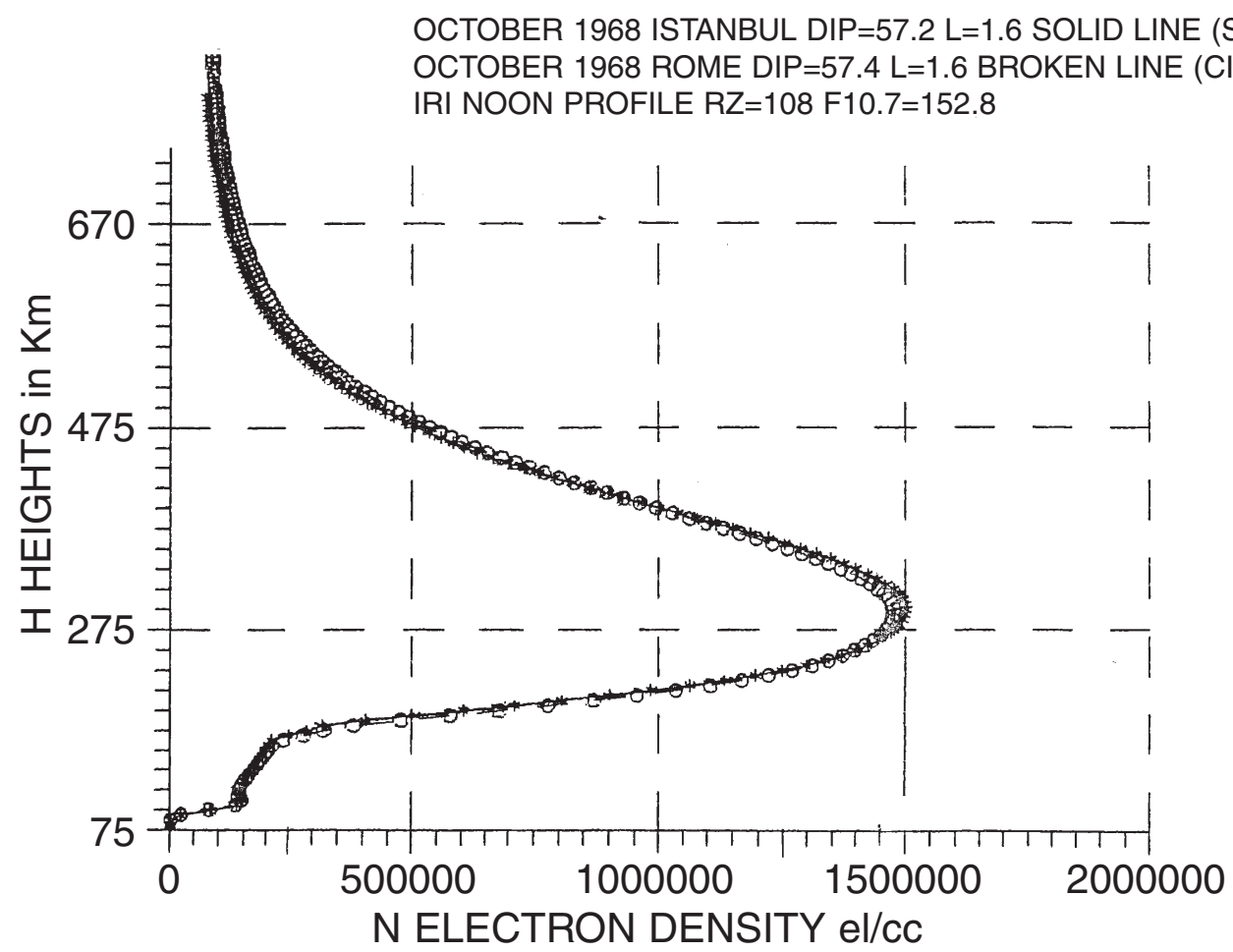

Fig. 1. Comparisons of the ionospheric heights $(\mathrm{km})$ versus electron density $(\mathrm{Ne} / \mathrm{cc})$ generated noon profiles of IRI for Istanbul solid-line (stars) and Rome broken-line (circles) plotted simultaneously.

with geographic coordinates $\varphi=41^{\circ} 08^{\prime} 11^{\prime \prime} \mathrm{N}$; $\lambda=29^{\circ} 01^{\prime} 58^{\prime \prime} \mathrm{E}$ and geomagnetic coordinates $\phi=38^{\circ} 40^{\prime} \mathrm{N} ; \Lambda=107^{\circ} .76 \mathrm{E}$; geocentric $\mathrm{DIP}=57^{\circ} .2$. IIAI ionosonde used automatic sweep 1.4-20 $\mathrm{MHz}$ and operated $40 \mathrm{~kW}$ pp during the complete 20th solar cycle (1963-1974) (Agopyan, 1994; Ozguc et al., 1998; Ozcep and Orbay, 1999).

Magnetic recordings of GSs and ionospheric soundings for ISs from 28th October 1968 to 2nd November 1968 with geomagnetic 3hourly magnetic activity index Kp reaching up to 7 to 8 values are considered. During the month of October $H$ mean was $-16.1 \mathrm{nT}$ but in November the $H$ mean was $=-32.5 \mathrm{nT}$ (around twice of the annual mean value $=-16.1 \mathrm{nT}$ ).

The geomagnetic field disturbances during this time interval are reported in Agopyan, 2002, figure 6 . The maximum disturbance in $H$ component is reached on 31 st October around 21UT. In the first storm day the ionospheric height changes are well over $250 \mathrm{~km}$. Leitinger et al., (2004) give slab thickness $(\tau)$ values at midday as $320 \mathrm{~km}$ and at midnight as $340 \mathrm{~km}$ over RO using SIRO data during October 1981. Whereas on 29th October IST measured $\mathrm{NmF} 2=7 \times 10^{11} \mathrm{e} / \mathrm{m}^{3}$, Zhang et al., (2003) give values for $\mathrm{RO}$ as $\mathrm{NmF} 2=1 \times 10^{-6} / \mathrm{cm}^{-3}$ for 15 th July 2000.

Using new IRI 2007 model (http://IRI.gsfc.nasa.gov 2008) no changes in height occurs during sunlight hours but electron density $(\mathrm{Ne})$ changes are very significant during 18LT hrs for RO and 19LT hrs for IST simultaneously. At $\mathrm{h}=300 \mathrm{~km}$ the maximum electron density $(\mathrm{Nm})$ of RO $\left(\mathrm{Nm}=8 \times 10^{11} \mathrm{~m}^{-3}\right)$ shows approximately $\Delta \mathrm{Nm}=4 \times 10^{11} \mathrm{~m}^{-3}$ concentration difference as max 


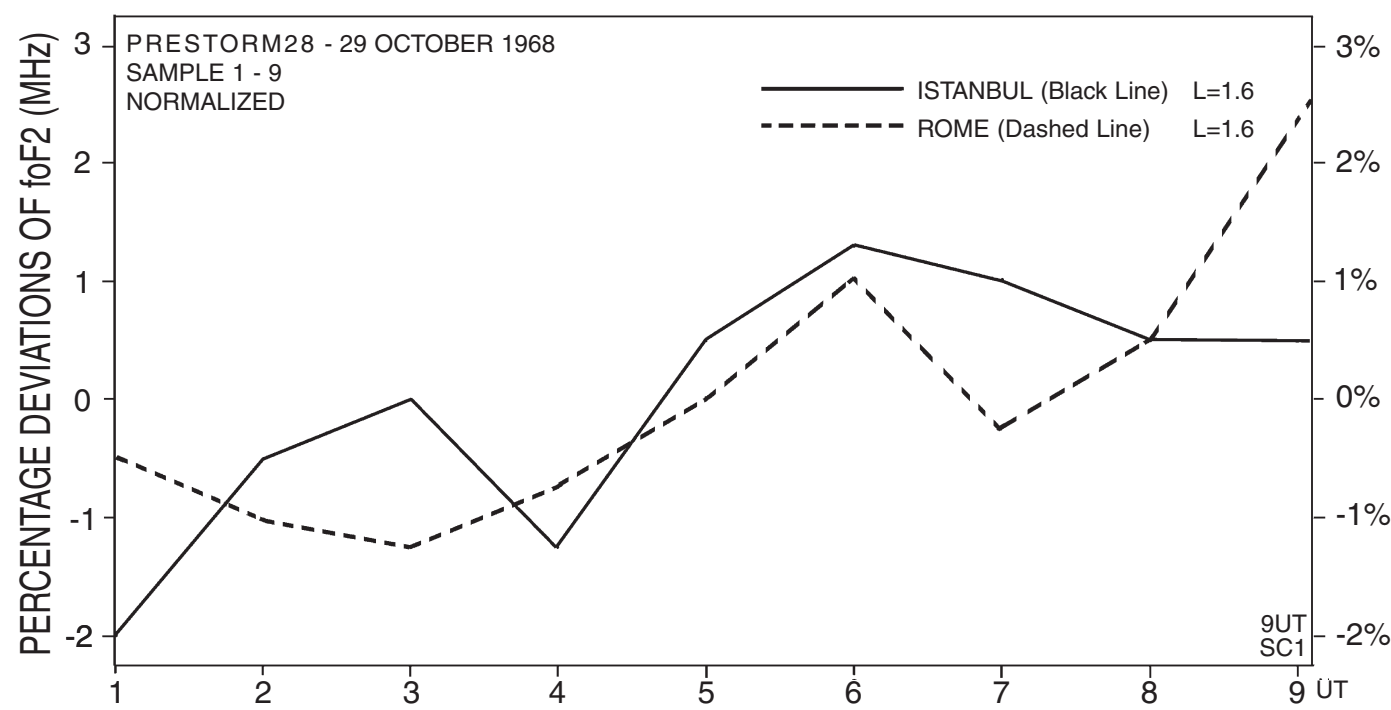

Fig. 2. Comparisons of normalized prestorm analysis as percentage deviations of foF $2(\mathrm{MHz})$ from monthly medians for Istanbul (black-line) and Rome (dashed-line) plotted simultaneously.

Ne value deviation from IST $\left(\mathrm{Nm}=4 \times 10^{11} \mathrm{~m}^{-3}\right)$ and this amount of $\Delta \mathrm{Nm}=4 \times 10^{11} \mathrm{~m}^{-3}$ means 0.4 Tera electrons per meter cube or an excess concentration of 400 billion of electrons per cubic meter. Then, between IST and RO, for the Day 28th October 1968, IST shows a height of 325 $\mathrm{km}$ and $\mathrm{Nm}=4 \times 10^{11} \mathrm{~m}^{-3}$ at $18 \mathrm{LT}$, simultaneously RO shows the same height and $\mathrm{Nm}=8 \times 10^{11} \mathrm{~m}^{-3}$ at 19LT. Consecutively, $\Delta \mathrm{Nm}$, max Ne value deviations at the same UTS hours of the stormy days at IST (at 18LT) and RO (at 19LT) are the following empirical reproductions generated from IRI 2007 model:

$\Delta \mathrm{Nm}=0.37 \times 10^{12} \mathrm{~m}^{-3}$ on 28 th. 10.1968 (prestorms), $\Delta \mathrm{Nm}=0.42 \times 10^{12} \mathrm{~m}^{-3}$ on 29.10 .1968 (storms), $\Delta \mathrm{Nm}=0.40 \times 10^{12} \mathrm{~m}^{-3}$ on 30 th. 10.1968 (poststorms, positive phases of positive ISs

$\Delta \mathrm{Nm}=0.43 \times 10^{12} \mathrm{~m}^{-3}$ on 31 st.10.1968 (negative phases and negative ISs)

$\Delta \mathrm{Nm}=0.43 \times 10^{12} \mathrm{~m}^{-3}$ on $01 \mathrm{st} .11 .1968$ (positive and negative phases of ISs)

$\Delta \mathrm{Nm}=0.44 \times 10^{12} \mathrm{~m}^{-3}$ on $02 \mathrm{nd} .11 .1968$ (poststorms, negative phases of ISs) respectively.

According to the reports by Prölss and Werner (2002) the largest storm effects have been observed at RO. By using the IRI-2000 ionospheric model, applied to RO data, a high degree of reliability during quiet conditions and inadequate degree of reliability during storm events has been shown (Cander, 2003; Zolesi and Cander, 2004).

\section{Results of comparisons}

The percentage frequency $(\mathrm{MHz})$ deviations $\Delta f o F 2(\%)$ reached up to $70 \%$. The comparison plots of normalized prestorm analysis in fig. 2 showed a deviation of about $\pm 2 \%$. In both ionospheric stations the maximum electron densities were approximately $\mathrm{Nm}=1.45 \times 10^{6}$ $\mathrm{e} / \mathrm{cc}$, while the heights of the maximum were about $\mathrm{h}=280 \mathrm{~km}$.

Figure 3 shows the percentage deviation of foF $2(\mathrm{MHz})$ during the magnetic storm period of 5 days.

Planetary waves (periods of about 2-30 days) were predominantly of tropospheric origin and penetrated directly to heights slightly above $100 \mathrm{~km}$. They have to propagate upwards into the $F$-region ionosphere via an indirect 


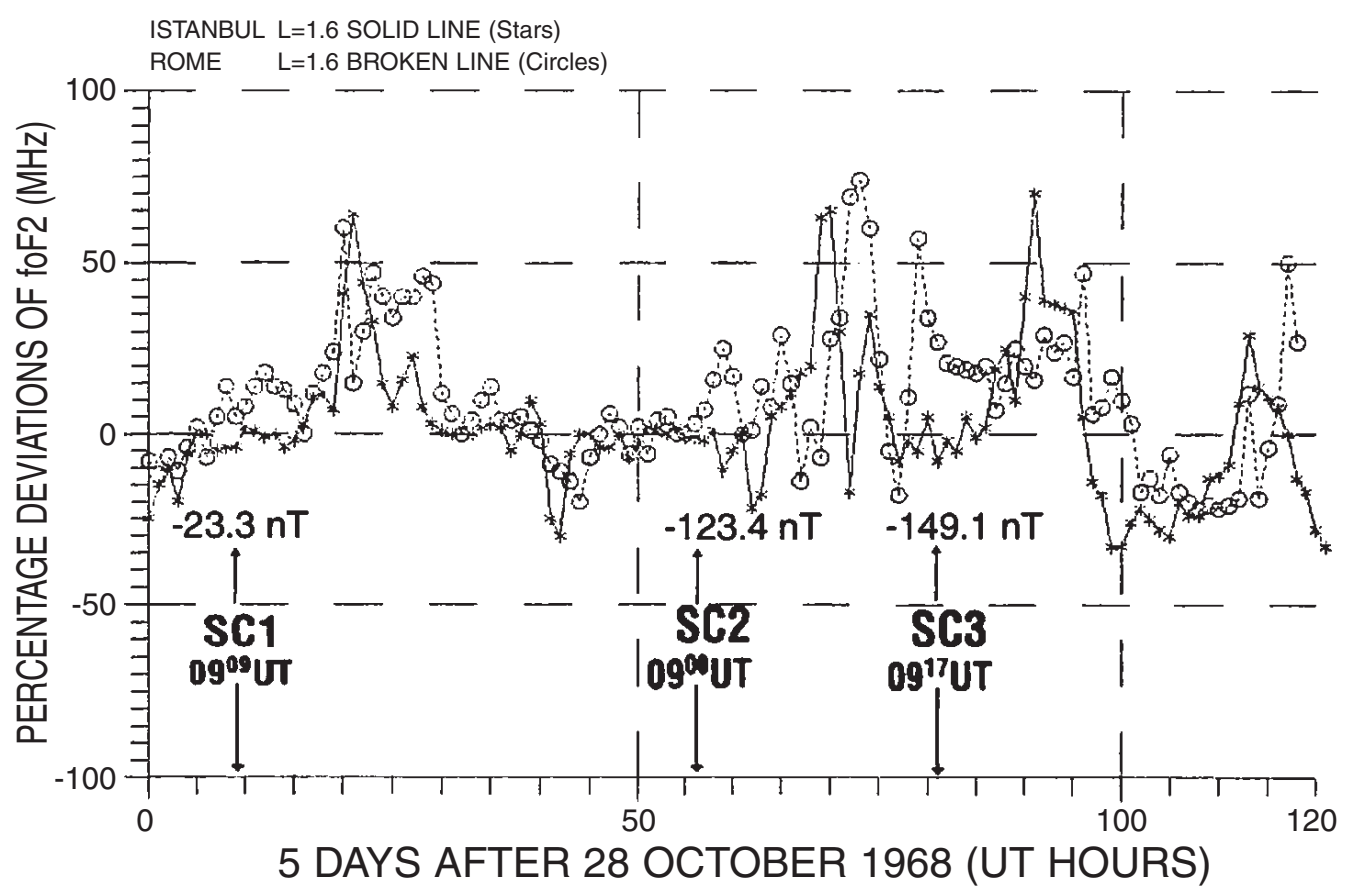

Fig. 3. Comparisons of percentage deviations of $f o F 2(\mathrm{MHz})$ from monthly medians versus time of 5 days after 29 October to 2 November 1968 for Istanbul solid-line (stars) and Rome broken-line (circles) plotted simultaneously.

route. Their effects were observed in the lower ionosphere, in the ionospheric $E$ region in $h^{\prime} E$ and sporadic- $E(E S)$ layer and in the $F 2$ region (e.g., Altadill and Apostolov, 2001; Lastovicka et al., 2006; Mikhailov et al., 2004). The quasi2-day wave in the Mesosphere Lower Thermosphere (MLT) was the most studied. Summarizing, it has been reported that the 2-day wave is a manifestation of both a global normal Rossby mode and a local unstable wave. Its activity is maximum during local summer and especially close to equinoxes (e.g., Altadill and Apostolov, 2001). Tides in the atmosphere are predominantly thermal, not gravitational tides. They are generated by the periodic solar heating. Dominant tidal periods in the ionosphere are $24 \mathrm{~h}$ and $12 \mathrm{~h}$.

The spectral analysis was applied to the Rome and Istanbul data. The power spectra including the Hanning windowing showed the effects of planetary waves (PW) with peaks at 2.3 days and tidal waves with diurnal and semidiurnal peaks, fig. 4.

It is also notable that during the negative phases of the IS, $\triangle f o F 2$ minimum value mostly restricting telecommunication channels and radio propagations observed over IST $(\triangle f o F 2=-33 \%)$ was $10 \%$ greater than that observed over RO $(\triangle f o F 2=-22 \%)$; whereas during the positive phases of the IS $\triangle f o F 2=+70 \%$ was observed over IST while in RO $\triangle f o F 2=$ was $+75 \%$.

\section{Conclusions}

Results of the analysis of the studied severe GSs presented here show complex mechanisms for the ionosphere at medium range scale as also partly seen in previous papers on IST using storm sudden commencements (SC) and ionospheric storms (IS) (Agopyan, 1986 and 2002). In this paper a comparison between RO and IST 


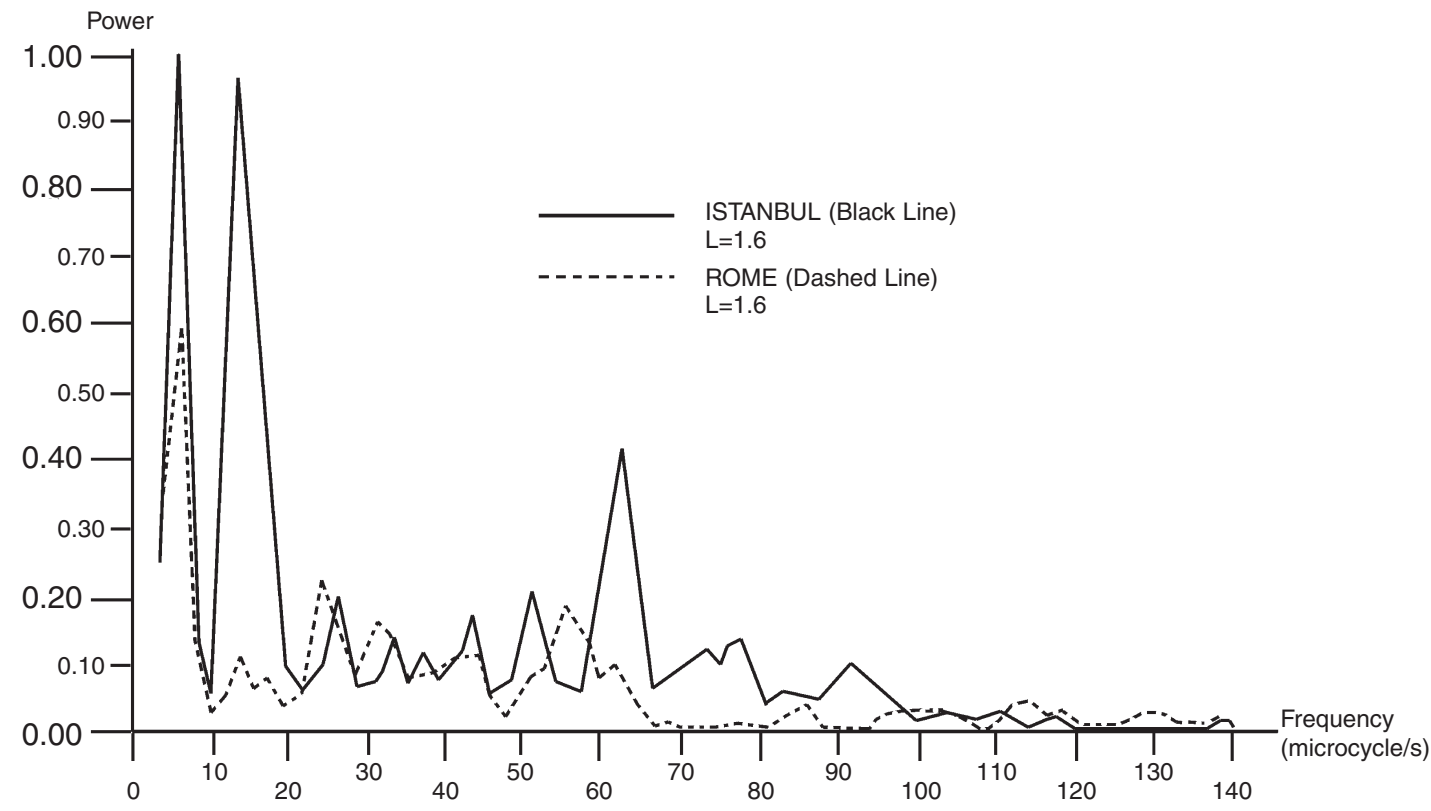

Fig. 4. Comparison results of power spectra of electron density values of the ionospheric severe storm including Hanning windowing for Istanbul (black-line) and Rome (dashed black-line) plotted simultaneously.

for the power spectral analysis on $f o F 2$ data showed peaks at 2.3 days and at $24 \mathrm{~h}$ (diurnal), $12 \mathrm{~h}$ (semidiurnal), 8h (teridiurnal) and 6h (quaterdiurnal) characteristics in both stations. The peaks magnitude was however weaker in RO. The morphological analysis of the two stations magnetic and ionospheric effect can be now compared and summarized as follows:

- FIRST STORM (1st SC at 09h09 UT on 29th October 1968, Kp=7): After the sudden commencement following weak ring currents, a rapid decrease of $\Delta \mathrm{H}$ and increase of $\triangle f o F 2$ on 30th October 1968 at $02 \mathrm{~h} \mathrm{LT}$ in IST, and 00h LT in RO, was observed simultaneously.

- SECOND STORM (2nd SC at 09h00 UT on 31st October 1968, $\mathrm{Kp}=8$ ): A very strong negative phase for $\Delta H$ started immediately after the SC indicating the strong effect of the ring current increase; the foF 2 data show small excursions following SCs exhibiting positive phase for RO but negative for IST. The largest positive response came with a delay about $8 \mathrm{hs}$ for IST but $12 \mathrm{hs}$ for RO with respect to SC.
- THIRD STORM (3rd SC at 09h17 UT on 1st November 1968, $\mathrm{Kp}=7$ ): An apparent $\Delta \mathrm{H}$ peak, with the rapid increase and decrease in negative phase which proves recovery of the intensive ring currents coinciding with a positive phase in $\triangle f o F 2$ and an elevation of the $F$ layer for both stations IST and RO were observed consecutively. The ionospheric positive and negative wavelike fluctuations were less significant in RO than in IST (Agopyan, 1994).

Negative phases last for a long time, even several hours after a SC and were observed in all three cases. Negative long-duration F2-layer storms are known to result from thermospheric neutral composition variations, namely, $\mathrm{O} / \mathrm{N} 2$ decrease (e.g., Prölss, 1995).

\section{Acknowledgements}

I wish to express my gratitude to Professors E. Boschi, P. Dominici, P. Spalla and also to S.M. Radicella, for their invitation, for provid- 
ing storm data, for the means used, and also for the international collaboration during the establishment of the Aeronomy and Radio propagation Laboratory in Italy where I carried out this study with the support of ICTP-TRIL Program.

\section{REFERENCES}

AgOPYAN, H. (1982): Ionospheric storms in connection with Geomagnetic storms, EGS and ESC Joint Meeting, Program and Abstracts Handbook, (August, Leeds, England), 110-17, A15, 23-27.

Agopyan, H. (1986): Ionospheric behavior on geomagnetic storms, in Proceedings of the International Symposium on «Radio Beacon Contribution to Study of Ionization and Dynamics of the Ionosphere and Corrections to Geodesy», edited by AntTI Taurainen (Oulu, Finland), 1, 11-25, ISBN 951-42-2256-3.

Agopyan, H. (1994): Magnetic and Ionospheric Storms in IST: An Observational Review, Journal of The Chamber of Geophysical Egineers of Turkiye, Geophysics, Jeofizik, edited by A.T. BASOKUR, 8 (2), 105-121, ISSN 0259-1472.

AgOPYAN, H. (2002): Severe magnetic storm effects on the ionosphere over Istanbul: a case study, Annals of Geophysics, 45 (5), 621-628.

Altadill, D. and E.M. Apostolov (2001): Vertical propagating signatures of wave-type oscillations (2- and 6.5days) in the ionosphere obtained from electron density profiles, Journal of Atmospheric and Solar-Terrestrial Physics, 63, 823-834

BilitZA, D. (1988 and 2008): Private Communications, (IRI 2008, URL:http://IRI.gsfc.nasa.gov)

Bulat, T., B. Zolesi, S., M. Radicella and H. Agopyan (1997): Comparison of ISs Observed Simultaneously in Istanbul and Rome, (ST3), XXII G. Assembly of the European Geophysical Society, 21-25 April 1997, Vienna, Austria, Ionosphere and Thermosphere, Space and Planetary Sciences, Editor: Prof. Dr. Arne K. Richter, Annals Geophysicae, Part III, (ST034), vol. 15, supp. III, 628

CANDER, L.J.R. (2003): Toward Forecasting and Mapping Ionospheric space weather under the COST actions, Adv. Space Res., 31 (4), 957-964.

DAvIES, K. (1981): Review of recent in Ionospheric predictions, Radio Science, 16, 1407-1430.

KAMIDE, Y. and A.D. RiCHMOND (1986): Recent advances in studies of Magnetosphere-Ionosphere coupling, $J$. Geomagnetism and Geo-electricity, 38 (7), 653.

LaštovičKa, J., A.V. Mikhailov, T. Ulich, J. Bremer,
A.G. Elias, N. Ortiz De Adler, V. Jara, R. Abarca Del Rio, A.J. Foppiano, E. Ovalle and A.D. Danilov (2006): Long-term trends in foF2: A comparison of various methods, Journal of Atmospheric and SolarTerrestrial Physics, 68 (17), 1854-1870.

Leitinger, R., L. Ciraolo, L. Kersley, S.S. Kouris and P. Spalla (2004): Relations between electron content and peak density: regular and extreme behaviour, in «COST 271 Action, Effects of Upper Atmosphere on Terrestrial and Earth Space Communications, Final Report», Annals of Geophysics, suppl. vol. 47 (2-3), 1097-1107.

Mikhailov, A.V., A.Kh. Depueva and T.YU. LeschiNSKAYA (2004): Morphology of quiet-time $F 2$-layer disturbances: high to lower latitudes, Int. J. Geomagn. Aeronom., 5 (1), GI-1006.

OzCEP, F. and N. OrbaY (1999): Interaction between Physics and the Earth: Geophysics in the 75th year of the republic of Turkey (Yerküre ile Fiziksel iletisim: Cumhuriyetin 75.yilinda ülkemizde Jeofizik) Istanbul University Engineering Faculty's Earth Sc. Rev., 12 (1), 99-105.

Ozguc, A., T. Atac, Y. Tulunay and L. Stanislawska (1998): The ionospheric foF2 data over Istanbul and their response to solar activity for the years 1964-1969 and 1993, Studia Geoph. et Geod., 42, 112-118.

PRÖLSS, G.W. (1995): Ionospheric F-region Storms, Handbook of Atmospheric Electrodynamics, edited by $\mathrm{H}$. Volland, , vol. II, (CRC Press, Boca Raton), pp. 195248.

PRÖLSS, G.W. and S. WERNER (2002): Vibrationally excited nitrogen and oxygen and the origin of negative ionospheric storms, Journal Geophys. Res., 107, A2,10.1029/2001JA900126, SIA 1-6.

RAwER, K and D. BILITZA (1989): Electron density profile description in the IRI, Journal of Atmospheric and Solar-Terrestrial Physics, 51, 781-790.

SchunK, R.W. (1996): Handbook of Ionospheric Models Solar-Terrestrial Energy Program, August, STEP, 1, 73-295

Titheridge, J.E. (1988): Private Communications.

Zolesi, B. and L.J.R. CANDER (eds) (2004): Cost 271 Action, Effects of the upper atmosphere on terrestrial and earth space communications: introduction, Final Report, First Section, Annals of Geophysics, Suppl. vol. 47 (2/3), 915-925.

Zhang, Y, L.J. Paxton, H. Kil, C.-I Meng, S.B. Mende, H.U. FREY and T.J. IMMEL (2003): Negative ionospheric storm seen by the IMAGE FUV instrument, Journal Geophys. Res., $\mathbf{1 0 8}$ (A9), 1343, doi: 10 1029/2002JA009797, 2003 (SIA, 4-7).

(received, July 14, 2008; accepted, May 28, 2009) 